\title{
Exploração das reservas petrolíferas do pré-sal, papel da Petrobras e os novos marcos regulatórios
}

\author{
Armando João Dalla Costa* \\ Elson Rodrigo de Souza-Santos ${ }^{* *}$
}

RESUMO - O objetivo desse trabalho é abordar as mudanças propostas na legislação atual que regulamenta o setor petrolífero no Brasil e o modelo proposto para ser utilizado como base na exploração das jazidas petrolíferas do pré-sal. Em um primeiro momento apresentamos o que são as jazidas petrolíferas do pré-sal e quais as suas características considerando os dados atuais. Posteriormente, abordamos qual foi o papel da Petrobras nessas descobertas e como desenvolveu tecnologia para viabilizar a sua exploração, seguida pela discussão sobre o que é a legislação atual, as suas deficiências e as propostas de mudança. Finalmente, discutindo o que é o modelo de exploração que se desenha para o pré-sal e quais são as dificuldades e desdobramentos econômico-financeiros.

Palavras-chave: Pré-sal. Petrobras. Marco regulatório. Exploração.

\section{INTRODUÇÃO}

Em novembro de 2008, a Petrobras, em conjunto com o governo do presidente Luiz Inácio Lula da Silva, anunciou a descoberta de grandes jazidas petrolíferas ao longo da costa brasileira denominadas genericamente de pré-sal. Segundo os dados preliminares, as estimativas indicam que as jazidas estão localizadas entre os litorais dos estados de Santa Catarina e Espírito Santo, de dimensões aproximadas de 800 por $200 \mathrm{~km}$, sendo que a maior parte das reservas se localiza a profundidades de cinco a sete mil metros (CONGRESSO NACIONAL, 2009, p. 21 - 22). O montante de petróleo das jazidas é estimado em algo entre 50 a 100 bilhões de barris (bbl) $)^{1}$ e a quantidade de gás natural provavelmente também muito grande sendo ainda mais difícil de ser estimada.

Caso as estimativas estejam corretas, o Brasil seria alçado a posição de um dos países que detém as maiores reservas petrolíferas do mundo, mas que traz consigo a necessidade de

\footnotetext{
* Doutor pela Université de Paris III (Sorbonne Nouvelle) e Pós-Doutor pela Université de Picardie Jules Verne, Amiens. Professor do Departamento de Economia e do Programa de Pós-Graduação em Desenvolvimento Econômico da UFPR. Coordenador do Núcleo de Pesquisa em Economia Empresarial. Endereço eletrônico: ajdcosta@ufpr.br.

** Mestrando do Programa de Pós-Graduação em Desenvolvimento Econômico pela Universidade Federal do Paraná, membro do Núcleo de Pesquisa em Economia Empresarial - NUPEM. Bolsista do CNPq. Endereço eletrônico: elson129@gmail.com.

${ }^{1}$ Uma unidade de bbl equivale a 159 litros.
} 
grandes investimentos para a sua viabilização, novos marcos regulatórios e modelo de exploração para revertê-los em benefício de toda a sociedade. Tanto que o Presidente Lula passou a enfatizar em seus discursos os benefícios que a exploração das jazidas do pré-sal podem trazer ao o país à medida que proporciona recursos para os mais diversos programas de Estado, principalmente sociais, educação e defesa. Entretanto, antes é necessário discutir como e qual a melhor forma de fazê-lo, não sendo uma discussão restrita no âmbito do governo, mas de toda a sociedade.

Dessa forma, o objetivo desse trabalho é explorar essas questões em quatro seções. A primeira apresenta o que é o pré-sal. A segunda é sobre a construção das vantagens competitivas da Petrobras em relação à exploração de petróleo em águas profundas e ultra profundas. A terceira explora a legislação atual que regulamenta o setor petrolífero, a motivação da sua alteração e qual a principal proposta. Por fim, abordar qual o modelo de exploração proposto também relacionado à alteração do marco regulatório.

\section{O QUE É PRÉ-SAL?}

Em novembro de 2008 foi anunciado através do comunicado conjunto do governo do presidente Lula e Petrobras que confirmava as evidências da existência de grandes jazidas petrolíferas no subsolo marinho brasileiro, denominadas genericamente de pré-sal. Segundo o estudo do Congresso Nacional (2009, p. 21), os dados preliminares indicam que as jazidas estão situadas entre os litorais dos estados de Santa Catarina e Espírito Santo, de dimensões aproximadas de 800 por $200 \mathrm{~km}$, abrangendo uma área estimada próxima a $112 \mathrm{mil} \mathrm{km²}$, onde 41 mil estão concedidos para exploração, sendo que a maior parte das reservas se localiza a profundidades de cinco a sete mil metros (ver Figura 1). O montante de óleo é estimado entre 50 a 100 bilhões de bbl, também contando uma quantidade gás natural de difícil mensuração, mas provavelmente muito grande.

O montante de petróleo estimado para o pré-sal facilmente alçaria o Brasil entre os dez países que detém as maiores reservas de petróleo segundo os dados disponíveis em janeiro de 2008 e, portanto, anteriores ao anúncio do pré-sal (ver Gráfico 1). Entretanto, as informações públicas sobre reservas petrolíferas trazem consigo certa imprecisão, pois é uma informação importante para as estratégias das empresas petroleiras e dos países produtores, então os agentes podem ter interesses diversos e diferentes graus de cautela técnica em divulgá-las. Por exemplo, o campo de Tupi pertencente ao pré-sal que foi licitado em 2008. A Petrobras e o governo estimam as reservas entre 5 e 8 bilhões de bbl, mas a sócia britânica 
BG Group e a portuguesa Galp, respectivamente com 25\% e 10\% do projeto, preveem reservas de 12 a 30 (FOLHA ONLINE, 2008).

FIGURA 1 - LOCALIZAÇÃO DAS JAZIDAS PETROLÍFERAS DO PRÉ-SAL

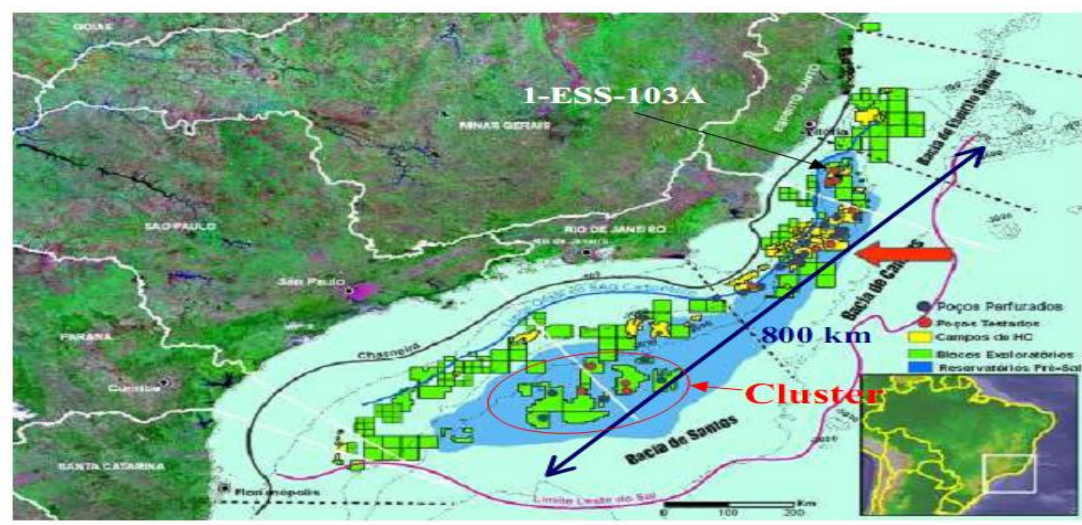

FONTE: Nepomuceno (2008)

A quantidade exata de óleo presente no pré-sal só será conhecida com pesquisas mais aprofundadas ao longo dos anos, mas os dados atuais indicam ser consideráveis. Porém, também é necessário considerar fatores como qualidade do óleo (facilidade de refino e produtividade), custo de extração, perspectiva em longo prazo do preço e consumo de petróleo no mercado internacional para verificar a viabilidade econômico-financeira. No momento, as duas frentes de exploração do pré-sal são a Cluster, na Bacia de Santos, que recebe os maiores investimentos, e Parque das Baleias, ao norte no litoral do Espírito Santo, uma área promissora devido as camadas de sal serem menos densas, menor lâmina da água e próximo ao litoral (ver Figura 1) (CONGRESSO NACIONAL, 2009, p. 35-36).

\section{GRÁFICO 1 - RESERVAS DE PETRÓLEO CONHECIDAS: JANEIRO/2008 (EM BI DE BBL)}

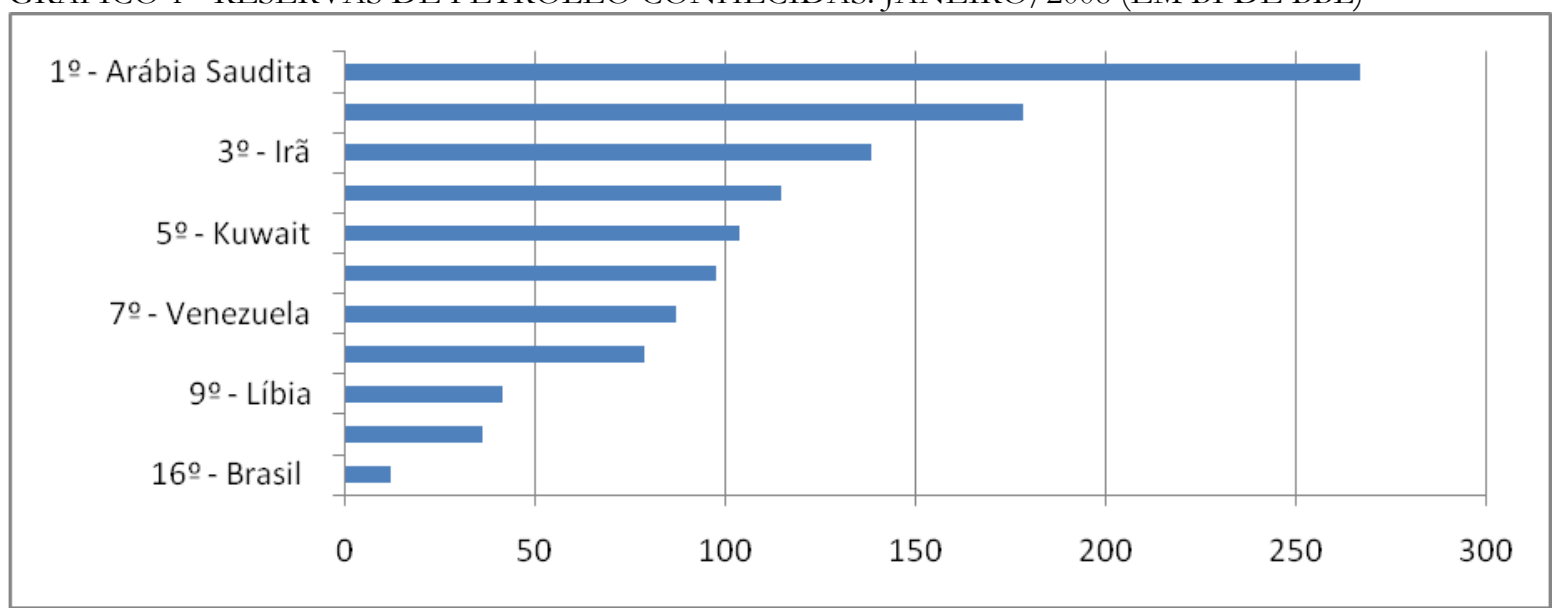

FONTE: CIA (2009)

Outro aspecto do pré-sal é a provável existência de grandes quantidades de gás natural, pois petróleo, gás e água salgada costumam ser encontrados em conjunto devido ao processo de formação das jazidas e, para retirar o petróleo, é necessário extrair também o gás 
natural. A mensuração da quantidade de gás é uma tarefa difícil, mas a declaração de Marco Tavares, diretor da empresa de consultoria Gás Energy, considerando apenas o campo de Tupi, estima que quando estiver em plena operação e dada a relação gás/óleo a produção de gás deve ser em torno de 120 milhões $\mathrm{m}^{3}$ por dia, onde de 70 a 80 podem ser oferecidos ao mercado. Assim, o campo de Tupi tem a capacidade para mais que suprir o mercado nacional atual de 60 milhões de $\mathrm{m}^{3}$. Para todo o pré-sal Marco Tavares diz que "é uma quantidade maluca, não vai ter mercado" (OLIVEIRA, 2008).

\section{PETROBRAS: VANTAGENS COMPETITIVAS E EXPLORAÇÃO DO PRÉ-SAL}

A Petrobras foi criada em 1953 pela Lei 2.004, sob o governo Getúlio Vargas (19511954), tendo como missão principal ser a gestora das reservas e do setor petrolífero no país e representante do Estado em relação à política energética ligada ao setor. Suas pesquisas e investimentos podem ser divididos em duas grandes fases, em que o ponto de inversão é representado pelos Choques do Petróleo da década de $1970^{2}$.

A primeira fase compreende o período da sua criação até aos Choques do Petróleo, caracterizada pelo intenso investimento na parte de refino e na rede de distribuição que desse capilaridade à distribuição de combustíveis e derivados. Na época, era fácil e barato obter petróleo no exterior e, assim, a prioridade da política do setor recaía em aprender e criar refinarias e aprender a beneficiar o óleo bruto vindo de fora. Para isso, a empresa efetuou grandes investimentos em pesquisa e desenvolvimento através do CENAP (Center of Oil Upgrade and Studies) criado em 1955, embrião do atual CENPES (Leopoldo Américo Miguez de Mello Research and Development Center) (PETROBRAS, 2009).

A segunda fase teve início com o advento dos Choques do Petróleo, onde os preços aumentaram, a oferta no mercado internacional foi reduzida e passaram a existir dificuldades de obtenção. A resposta do Brasil foi incentivar o uso de combustíveis alternativos como, por exemplo, o etanol por meio do Programa Nacional do Álcool (Pró-Álcool) e, no setor

\footnotetext{
2 Os Choques do Petróleo podem ser sintetizados em dois fatos. O primeiro ocorreu em 1973 quando a Organização dos Países Exportadores de Petróleo (OPEP), comandada pelos árabes, detinha grande parte da produção mundial de petróleo, promoveu deliberadamente o aumento de preços em virtude da retaliação ao apoio norte-americano e ocidental a Israel durante a Guerra do Yom Kippur (1973) resultando na vitória israelense sobre os países árabes da região. O segundo ocorreu em 1979 com a desorganização da produção petrolífera iraniana em virtude da emergência de instabilidades políticas que levaram ao poder um governo islâmico anti-norte-americano, agravado pela Guerra com o Iraque, outro importante produtor mundial, na década de 1980.
} 
petrolífero, explorar as jazidas nacionais, localizadas na maior parte no subsolo marinho, especialmente na Bacia de Campos. Até os choques do petróleo estas jazidas eram consideradas inviáveis devido ao baixo preço do petróleo. A partir de então passaram a ser a porta para a auto-suficiência e segurança energética. Assim, como observa Ortiz Neto (2006, p. 61), eram necessários grandes investimentos em tecnologia, capital físico e humano através de um longo processo de aprendizado. Apesar da exploração de petróleo offshore (no subsolo marinho) ser feita desde idos do século XIX nos Estados Unidos, a tecnologia existente era insuficiente para explorar as jazidas nacionais, levando a Petrobras a desenvolver tecnologias próprias.

Para isso a empresa passou a elevar a intensidade na pesquisa e investimento na exploração de petróleo offshore a partir de 1973, quando o CENPES começou a adaptar tecnologia importada ao ambiente, jazidas, geologia e condições de mercado (PETROBRAS, 2009). Em paralelo, a empresa firmava contratos de licenciamento junto a firmas estrangeiras experientes nesse tipo de exploração, em busca de transferência de tecnologia que incluía estágios dos engenheiros no exterior e difusão dos conhecimentos através de cursos internos (ORTIZ NETO, 2006, p. 66). Dessa forma, fazendo uso dos axiomas do aprendizado denotados por Malerba (1992), a Petrobras absorveu os conhecimentos disponíveis no mercado, posteriormente utilizados como base para seu próprio programa de desenvolvimento de tecnologia denominado Programa de Desenvolvimento Tecnológico de Sistemas de Produção em Águas Profundas (PROCAP).

O primeiro PROCAP começou em 1986 com o objetivo de melhorar a competência técnica na perfuração de pólos até mil metros. A segunda versão foi lançada em 1993, denominada PROCAP-2000 com o objetivo de avançar para exploração de poços de até dois mil metros de profundidade. Finalmente, a partir do ano de 2000, a Petrobras passou a trabalhar com o PROCAP-3000, voltado para viabilizar a exploração de jazidas com lâminas da água superiores a três mil metros que é o caso do pré-sal (PETROBRAS, 2009b). Estas pesquisas lhe proporcionaram um domínio tecnológico singular nesse tipo de exploração, também refletindo na facilidade em se associar a outras grandes petrolíferas (norte-americana ExxonMobil e espanhola Repsol, por exemplo) para explorar petróleo offshore tanto no Brasil quanto em outros países. Isso foi visto por Dalla Costa e Pessali (2007) como uma das molas impulsionadoras da sua internacionalização, com a exploração de jazidas petrolíferas tão diferentes quanto Colômbia, Angola, Irã, Paquistão e Portugal. 
O advento da Lei do Petróleo de 1997 (Lei 9.478) quebrou o monopólio da Petrobras e abriu o seu capital, levando a um movimento contraditório. De um lado, continua sendo um instrumento essencial da política energética do país e que desfruta da herança de ser por mais de 40 anos o monopolista oficial do setor. De outro, a participação de acionistas privados leva a mostrar que é bem gerida e busca lucros. O resultado dessa situação é que a Petrobras multiplicou por 10 vezes seus lucros entre 1997 e 2007, passou a atuar em outros campos, como energia elétrica e biocombustíveis, obteve a autossuficiência em petróleo, é uma das grandes petrolíferas do mundo e continua em expansão (ver Tabela 2).

TABELA 1 - NÚMEROS DA PETROBRÁS EM 2008

\begin{tabular}{lr}
\multicolumn{1}{c|}{ Dados } & Números \\
\hline Valor de Mercado - dezembro/2008 & US\$96 bilhões \\
Postos de Abastecimento & mais de 8 mil \\
Empregados - Junho/2009 & 75.240 \\
Plataformas de Produção & 112 \\
Termoelétricas & 18 \\
Refinarias & 15 \\
Produção Média de Petróleo por dia (em mil bbl) & 1.855 \\
Investimento Planejado - 2009 a 2013 & US\$174,4 bilhões \\
\hline
\end{tabular}

FONTE: Petrobras (2009c) e tabela elaborada pelos autores.

\section{MARCOS REGULATÓRIOS}

O advento da constatação de que o Brasil passaria a ser detentor de grandes reservas petrolíferas devido à confirmação técnica da existência do pré-sal levou ao movimento de estudar as modificações na legislação atual para torná-la condizente com a nova posição do país. Sendo assim, em um primeiro momento são identificados os problemas da legislação atual e quais as propostas para saná-los.

\subsection{A "LEI DO PETRÓLEO”}

O atual marco regulatório que versa sobre a exploração, produção e refino de petróleo e gás no Brasil teve origem na alteração da Constituição Federal de 1988, por meio da Emenda Constitucional n. 9, de 9 de novembro de 1995, aprovada no primeiro ano da gestão do governo Fernando Henrique, como parte de uma série de reformas que reduzissem o grau de intervenção do Estado brasileiro na economia. A Emenda permitiu que a União contratasse empresas estatais e privadas para exploração de petróleo e gás natural, dando amparo jurídico para uma reforma mais ampla do setor. Isso ocorreu com a Lei n. 9.478, de 6 
de agosto de 1997, também conhecida como "Lei do Petróleo" que implantou uma nova regulamentação do setor, retirando o monopólio da Petrobras, incentivando a competição e investimentos privados, a criação de instituições para a gestão do setor que substituíssem a Petrobras, como o Conselho Nacional de Política Energética (CNPE) e a Agência Nacional de Petróleo, Gás Natural e Bicombustíveis (ANP).

A partir da Lei do Petróleo, o privilégio da Petrobras escolher os campos de petróleo mais propícios a exploração, atuando como um braço do Estado brasileiro, foi eliminado. Em seu lugar foi instituído o sistema de rodadas de licitação, onde a empresa que oferece maior valor por certa área de exploração oferecida no leilão obtém o direito de explorá-la por 30 anos (OLIVEIRA, 2008). Esse aspecto do modelo é criticado pelo Congresso Nacional (2009. p. 27-28) exposto no seu caderno de Altos Estudos, em relação ao fato do Estado ter o seu monopólio sobre o produto explorado limitado por duas razões correlatas. Uma é que o Estado não tem a propriedade e nem participação no produto extraído, o que leva a redução de sua receita potencial.

$\mathrm{Na}$ época, o modelo de rodadas de licitação fazia sentido, pois era condizente com o tipo de reservas petrolíferas que se julgava existir no país, ou seja, poucas e de elevado risco. Portanto, o Estado teria mais vantagens em receber pela concessão antecipadamente, reduzindo os riscos e, na melhor das hipóteses, se beneficiando dos impostos cobrados pelo produto extraído em operação da empresa. Entretanto, o advento da área do pré-sal com grandes reservas petrolíferas e de baixo risco levam o modelo atual a ser inadequado na medida em que limita as receitas obtidas pelo Estado e o domínio sobre o produto extraído. Dessa forma, como argumenta o estudo do Congresso Nacional (2009), mantido o modelo atual o Estado teria como receita advinda de tributos e participações na exploração do pré-sal uma cifra em torno de $23 \%$ contra cerca de $78 \%$ do modelo Norueguês.

\subsection{PROPOSTAS DE NOVA REGULAMENTAÇÃO}

A necessidade de reformar a legislação da regulamentação do setor do petróleo estava em voga a partir de novembro de 2007, quando o CNPE, informado que estudos técnicos da Petrobras apontavam a existência de grandes volumes de petróleo e gás de alto valor comercial que, caso confirmados, seriam os maiores do mundo, localizados numa área denominada pré-sal, decidiu tomar medidas preventivas e preparar a readequação da legislação. Primeiramente instruiu à ANP para retirar da $9^{a}$ Rodada, marcada para o fim de novembro de 2007, 41 blocos e concluir a $8^{a}$ Rodada dependendo da avaliação sobre 10 
blocos, ambos de alto potencial exploratório e pertencentes às "franjas" do pré-sal. Além de iniciar medidas para preparar a alteração dos marcos legais e modelo de exploração, especialmente prevendo o contrato de partilha (ANP, 2008).

Em linhas gerais, os novos marcos regulatórios possuem um desenho preliminar verificado na audiência pública da ANP (2008) no Senado Federal, em junho de 2008, e no Caderno de Altos Estudos Estratégicos do Congresso Nacional (2009). Finalmente, em 31 de agosto de 2009, o governo Lula oficializou quais as propostas de Lei para readequar a legislação a ser enviada para aprovação e discussão no Legislativo Federal, não é a versão final, mas delineia o que é a nova regulamentação. Assim sendo, o discurso da Ministra da Casa Civil, Dilma Rousseff (2009) apresenta os quatro pontos fundamentais da proposta: produção partilhada; criação de uma empresa estatal para gerir os contratos; criação de um fundo para reaplicar os recursos advindos da exploração; e fortalecer a Petrobras.

Segundo a ANP (2008), o contrato de partilha da produção é aplicado principalmente em países com grandes reservas, onde o País-hospedeiro (a União), através de uma entidade inteiramente sua, totalmente estatal, contrata empresas para exploração e produção. O produto extraído pela empresa é de propriedade da União, onde a empresa contratada recebe a sua porcentagem em óleo ou moeda, de acordo com o contrato, levando em conta tributos e participações governamentais.

A entidade estatal citada é uma empresa pública que tem a função de gerir os contratos com as firmas que realizam a exploração e produção, defendendo os interesses do Estado, sem a intervenção de acionistas privados. Além do mais, como é uma administradora de contrato, não costuma ter a necessidade de ter mais que cem empregados e ocupa uma estrutura modesta. Na proposta do governo Lula, a empresa se chama Petrosal, justificada pela Ministra Dilma Rousseff (2009) como sendo um tipo de instituição comum nos grandes produtores de petróleo, envolvidos na administração de cerca de $77 \%$ das reservas mundiais.

O fundo é utilizado para a aplicação dos recursos que o Estado obtém com as jazidas petrolíferas em ações que tragam benefícios a toda a sociedade, melhorem a estrutura e competitividade do país e o fortaleça frente a instabilidades financeiras mundiais. No caso do pré-sal, segundo a Ministra Dilma Rousseff (2009), esse fundo é denominando de "Fundo Social" com os mesmos objetivos citados, fiscalizado pelo Legislativo, afastando a maldição do petróleo. A maldição também é chamada "doença holandesa" que gera a desorganização da economia do país rico em petróleo à medida que ocorre a valorização cambial derivada da entrada de divisas originada da exportação de petróleo bruto. 
O tripé formado pelo contrato partilhado, empresa pública e Fundo proposto pelo governo Lula tem forte inspiração no modelo norueguês, como previsto no estudo do Congresso Nacional (2009). A empresa pública norueguesa se chama Petoro, criada em 2001, tem no máximo 60 empregados, fiscalizada pelo Parlamento. Os recursos obtidos são destinados ao fundo soberano Government Pension Fund, também alimentado pelos impostos sobre a produção de petróleo e parcela dos lucros da empresa de economia mista StatoilHydro, a equivalente norueguesa da Petrobras (OLIVEIRA, 2009). Entretanto, a Ministra Rousseff enfatiza que o governo reafirma o compromisso de assegurar que os contratos lavrados anteriormente sejam honrados, pois também necessita da atração de investidores e recursos na ordem de US $\$ 600$ bilhões que só a Petrobras e o Estado brasileiro não têm condições de arcar. Além do mais é muito interessante para o país que as grandes petroleiras e suas fornecedoras invistam no Brasil para beneficiar o óleo no país e criem redes de fornecedores e de pesquisa.

O fortalecimento da Petrobras é uma necessidade, pois é a que melhor conhece a geologia da região e detém capacidade para viabilizar a exploração de petróleo e gás em águas profundas e ultraprofundas. Na proposta do governo (ROUSSEFF, 2009), a Petrobras terá uma participação mínima em todos os projetos de exploração, propostos preliminarmente em $30 \%$, sendo reservado ao Estado leiloar o direito de exploração ou concedê-lo diretamente a Petrobras. Onde a vencedora desses leilões oferecerem maior percentual da produção à União, a Petrobras acompanhará esse percentual. Não sendo descartada a cobrança de bônus na assinatura do contrato e a incidência de royalties segundo a Lei do Petróleo.

A opinião das petroleiras privadas sobre as mudanças na legislação geralmente são negativas. O que pode ser sintetizado na declaração do Instituto Brasileiro de Petróleo, Gás e Bicombustíveis (IBP) que defende "a manutenção, com alguns ajustes, do modelo de concessão atual - competitivo, transparente e estável". A entidade representa as principais companhias do setor petrolífero brasileiro, incluindo Repsol e Exxon Mobil (ELLSWORTH, 2009). A negativa dessas petroleiras pode ser explicada pela perda de receita devido a maior participação do Estado, conjugado com a menor autonomia na administração do produto extraído. O que não quer dizer que os investimentos no pré-sal e no beneficiamento do óleo em território nacional deixem de ser atraentes, como não deixaram de investir em países com legislações no mesmo formato, por exemplo, a Noruega. 


\section{MODELO DE EXPLORAÇÃO}

As reservas petrolíferas só podem ser revertidas em benefício do país se forem exploradas e comercializadas, adicionalmente é interessante ao país criar uma rede de fornecedores e desenvolvedores de tecnologia como também investir no beneficiamento do óleo bruto passando a exportar derivados que têm maior valor agregado. Para isso são necessários grandes investimentos com maturação de longo prazo, que crescem proporcionalmente a dificuldade de exploração da jazida. Outro fator que é necessário considerar é a política de segurança energética de cada país e como influencia na exploração interna de petróleo. A Tabela 2 mostra essas discrepâncias ao comparar quem são os dez maiores reservas com os dez maiores produtores.

TABELA 2 - RESERVAS PETROLÍFERAS VERSUS PRODUÇÃO: 2007-2008

\begin{tabular}{|c|c|c|c|}
\hline \multicolumn{2}{|c|}{ Reservas petrolíferas (em bi de bbl) } & \multicolumn{2}{|c|}{ Produção (em mi de bbl por dia) } \\
\hline $1^{\circ}$ - Arábia Saudita & 267 & $1^{\circ}-$ Rússia & $9,980,000$ \\
\hline $2^{\circ}$ - Canadá & 179 & $2^{\circ}$ - Arábia Saudita & $9,200,000$ \\
\hline $3^{\circ}-$ Irã & 138 & $3^{\circ}$ - Estados Unidos & $8,457,000$ \\
\hline $4^{\circ}$ - Iraque & 115 & $4^{\mathrm{o}}-\mathrm{Irã}$ & $4,700,000$ \\
\hline $5^{\circ}-$ Kuwait & 104 & $5^{\circ}-$ China & $3,725,000$ \\
\hline $6^{\circ}$ - Emirados Árabes Unidos & 98 & $6^{\circ}-$ México & $3,501,000$ \\
\hline $9^{\circ}-$ Venezuela & 87 & $7^{\circ}$ - Canadá & $3,425,000$ \\
\hline $8^{\circ}$ - Rússia & 79 & $8^{\circ}$ - Emirados Árabes Unidos & $2,948,000$ \\
\hline $9^{\circ}-$ Líbia & 41 & $9^{a}$ - União Europeia & $2,676,000$ \\
\hline $10^{\circ}$ - Nigéria & 36 & $10^{\circ}$ - Venezuela & $2,667,000$ \\
\hline
\end{tabular}

FONTE: CIA (2009) e CIA (2009b), tabelas elaboradas pelos autores.

Os casos mais emblemáticos são dos Estados Unidos, China e Iraque. Os Estados Unidos e a China não figuram sequer entre as dez maiores reservas, mas ocupam, respectivamente, a terceira e quinta posições em relação à produção. Uma das explicações é que para esses países o petróleo é encarado como um insumo vital para sua matriz energética e funcionamento de sua economia. Dessa forma, incentivar a produção interna figura como maneira de garantir parte das suas necessidades de petróleo, dando maior margem de manobra para negociar com os países fornecedores. Portanto, mesmo sendo mais custoso explorar as suas jazidas petrolíferas, explorá-las faz parte da política de segurança energética do país. A mesma lógica pode ser aplicada ao Brasil e justifica a busca pela autossuficiência.

O Iraque detém a quarta maior reserva petrolífera, mas não aparece nem entre os dez maiores produtores. A justificativa mais evidente diz respeito a instabilidade política resultante da Guerra do Iraque, iniciada em 2003, e subsequente ocupação por tropas norteamericanas e de seus aliados, desorganizando a estrutura de produção. Outro motivo, mais profundo, está relacionado a instabilidade derivada da fragilidade do Estado-nação, 
fortalecido artificialmente com as divisas e poder advindos da exportação de petróleo, tido como principal ou único produto relevante. Dessa forma, os grandes consumidores de petróleo, especialmente os Estados Unidos, agem tanto política quanto militarmente para garantir alguma estabilidade e o apoio desses países, também como parte da sua estratégia de segurança energética.

Em relação ao custo de extração de cada bbl do pré-sal deve ter o custo médio $50 \%$ superior ao custo das jazidas atuais devido a maior profundidade, em outras palavras, o custo médio de US\$ 10 por bbl deve saltar para US\$ 15 (CONGRESSO NACIONAL, 2009, p. 4546). Entretanto, nos primeiros poços em testes de produção do pré-sal nas reservas de Tupi, segundo o presidente da Petrobras, Sergio Gabrielli, os custos são de US\$ 45 (G1, 2009), mas devem cair à medida que a exploração se consolidar e os problemas encontrados forem equacionados.

Como subproduto dos investimentos para exploração do pré-sal é o incentivo a instalação e criação de uma rede de fornecedores de equipamentos e serviços tal como o desenvolvimento de tecnologias. A ideia preliminar proposta pelo BNDES é reunir toda a estrutura em um mesmo município, nos moldes da cidade americana de Houston e outros exemplos encontrados na Noruega e na Coreia (LORENZI, 2009). Isso é essencial para viabilizar o plano da Petrobras de praticamente dobrar a produção em dez anos, saltando dos atuais 2 milhões de bbl dia para mais de 4, entre os anos de 2009 e 2019. Como também fornecer a estrutura para beneficiar o óleo, onde são ventilados incentivos fiscais e outras medidas que favoreçam esse tipo de investimento por companhias privadas além da Petrobras.

Diferente do óleo e derivados o gás natural tem grandes dificuldades de ser exportado devido as suas restrições de transportes em navios originado de sua natureza gasosa e o alto custo consequente, mas que acaba sendo extraído para viabilizar a do óleo. Dessa forma, no caso do pré-sal, o gás natural tende a ser adicionado a matriz energética brasileira. Por exemplo, Marco Tavares, da consultoria Gas Energy, propõe a instalação de plantas de liquefação do gás em alto-mar para viabilizar o transporte em navios até os terminais onde seria distribuído para o resto do país (OLIVEIRA, 2008). Outra opção seria a instalação de termoelétricas em alto mar que gerariam energia a partir do gás natural e enviariam ao continente por cabos submarinos, mais viável do que tubulações para transporte de gás devido a elevada profundidade e pressão. 


\section{CONSIDERAÇÕES FINAIS}

Nesse trabalho foram abordados os aspectos relacionados à exploração, novos marcos regulatórios e o papel da Petrobras na exploração das jazidas petrolíferas do pré-sal. Essas jazidas têm o potencial de alçar o Brasil no seleto grupo de detentores das maiores reservas do mundo, como também, dos maiores produtores e exportadores. Entretanto, essa nova posição brasileira em relação ao petróleo exige novos marcos regulatórios, modelo de exploração, polpudos investimentos em exploração e beneficiamento, mecanismos que as transformem em benefício para a sociedade como um todo. No ano de 2009, após discussões internas, o governo Lula apresenta os principais pontos da proposta a serem discutidos pelo legislativo e toda a sociedade, mas que dá os primeiros indícios do que será. Em linhas gerais, é muito semelhante ao modelo norueguês que prevê: uma empresa pública para gerir os contratos e defender os interesses do Estado; a produção partilhada para que o Estado obtenha maior participação na renda; a criação de um fundo para reaplicar os recursos provenientes da exploração e evitar a maldição do petróleo. De outro lado, é importante ressaltar que a exploração do pré-sal passa pelo fortalecimento da Petrobras devido as suas grandes vantagens competitivas e ter como grande acionista o Estado brasileiro, mas os investimentos privados e o papel das grandes petroleiras é igualmente importante, especialmente no beneficiamento do óleo. 


\section{REFERÊNCIAS}

ANP (2008). Audiência Pública - Continuidade do Processo Exploratório de P\&G no Brasil. Disponível em: <http://www.anp.gov.br/doc/conheca/02_06_08\%20Aud\%20Pud\%20

CAE $\% 20$ marco $\% 20 \mathrm{pr} \% \mathrm{C} 3 \% \mathrm{~A} 9 \% 20$ sal.ppt>. Acesso em: 5/8/2009.

BRASIL. Emenda constitucional n. ${ }^{\circ}$, de 9 de novembro de 1995. Diário Oficial da União, 10 nov. 1995.

BRASIL. Lei n. ${ }^{\circ}$ 2.004, de 3 de outubro de 1953. Diário Oficial da União, 3 out. 1953.

BRASIL. Lei n. ${ }^{\circ}$ 9.478, de 6 de agosto de 1997. Diário Oficial da União, 6 ago. 1997.

CIA. (2009a). The World Factbook - Country comparison: oil - proved reserves. Disponível em: <https://www.cia.gov/library/publications/the-world-factbook/rankorder/

rawdata_2178.text $>$. Acesso em: 8/8/2009.

CIA. (2009b). The World FactBook - Country Comparison: oil - production. Disponível em: $<$ https://www.cia.gov/library/publications/the-world-factbook/rankorder/

rawdata_2173.text> Acesso em: 8/8/2009.

CONGRESSO NACIONAL. Os desafios do pré-sal. Cadernos de Altos Estudos, Brasília, n. $5,2009$.

DALLA COSTA, A. J.; PESSALI, H. F. A experiência de internacionalização da Petrobras. In: VII Congresso Brasileiro de História Econômica e $8^{a}$ Conferência Internacional de História de Empresas, 2007, Aracaju-SE.

ELLSWORTH, B. Petroleiras preferem modelo de concessões no pré-sal, diz IBP. Último Segundo, 27 agosto 2008. Disponível em: <http:/ /ultimosegundo.ig.com.br/economia/

2009/08/27/petroleiras + preferem + modelo + de + concessoes + no + pre + sal + diz $+\mathrm{ibp}+812192$ 5.html>. Acesso em: 2/9/2009.

FOLHA ONLINE. (2008). Entenda o Que é a Camada pré-sal. Disponível em: <http://www1.folha.uol.com.br/folha/dinheiro/ult91u440468.shtml>. Acesso em: $5 / 6 / 2009$.

G1. (2009). 'O pré-sal não é uma vaca leiteira,' diz Gabrielli. Disponível em: <http://g1.globo.com/Noticias/Economia_Negocios/0,_MUL1290603-9356,00-

$\mathrm{O}+\mathrm{PRESAL}+\mathrm{NAO}+\mathrm{E}+\mathrm{UMA}+\mathrm{VACA}+$ LEITEIRA+DIZ+GABRIELLI.html $>$ Acesso em: $3 / 9 / 2009$.

LORENZI, S. BNDES sugere ao governo polo industrial para o pré-sal. JB Online, 2 setembro 2009. Disponível em: <http://jbonline.terra.com.br/pextra/2009/09/02/ e020927880.asp>. Acesso em: 2/9/2009.

MALERBA, F. Learning by firms and incremental technical change. Economic Journal, v. 102, p. 845-859, jul. 1992.

NEPOMUCENO, F. Experiências da Petrobras no caminho do pré-sal. In: Rio Oil \& Gas Conference, 2009, Rio de Janeiro. Disponível em: < www2.petrobras.com.br/ri/pdf/

RioOilGas_2008_Nepomuceno.pdf>. Acesso em: 5/6/2009.

OLIVEIRA, N. de. Pré-sal deve produzir 120 milhões de metros cúbicos de gás natural por dia, diz consultor. Agência Brasil, 16 setembro 2008. Disponível em: <http://www.agenciabrasil.gov.br/noticias/2008/09/16/materia.2008-09-16.7156064568 /view>. Acesso em: 2/8/2009. 
ORTIZ NETO, J. B. O processo de aprendizado tecnológico na trajetória do sistema de produção flutuante empreendido pela Petrobras em seu programa de capacitação tecnológica em águas profundas - PROCAP. Dissertação (Mestrado em Desenvolvimento Econômico) - Programa de Pós-Graduação em Desenvolvimento Econômico - PPGDE, Setor de Ciências Sociais Aplicadas, Universidade Federal do Paraná, Curitiba, 2006.

PETROBRAS. (2009). Technology: Petrobras Research Center - The Birth of Cenpes. Disponível em: <http://www2.petrobras.com.br/portal/frame.asp?pagina=/tecnologia/ing/ $>$ Acesso em: 21/6/2009.

PETROBRAS. (2009b). Tecnologia: área de atuação - produção em águas profundas. Disponível em: <http://www2.petrobras.com.br/tecnologia2/port/areadeatuacao_ exploracaoaguas.asp\#01>. Acesso em: 18/6/2009.

PETROBRAS. (2009c). Relatório Anual 2008. Disponível em: <http://www2.petrobras. com.br/ri/port/ConhecaPetrobras/RelatorioAnual/pdf/RelatorioAnual_2008.pdf> Acesso em: 5/8/2009.

ROUSSEFF, D. (2009). Discurso da Ministra-chefe da Casa Civil, Dilma Rousseff, no Ato de anúncio da proposta de um novo modelo regulatório para a exploração das jazidas do pré-sal. Disponível em: <http://www.info.planalto.gov.br/download/discursos/pr14152@.doc> Acesso em: 7/9/2009. 